\title{
The Cultivation Mode of Minority Secretary Major Based on OpenAPI Experimental Model
}

\author{
LiuYuehua \\ Nanchang Institute of Science \&Technology,Nanchang 330108,China
}

\begin{abstract}
Keywords: DRM control model; minority ;secretary major; ; diverse intelligent; ODRL model; OpenAPI authentication
\end{abstract}

\begin{abstract}
With the development of economic globalization, the cultivation of minority secretary major should follow the principle of compound talents training mode and improve the overall quality of the talent of minority secretary major. Secretary major training plan has shortage of teaching content and lacks cross-cultural communication training program. Its teaching mission objectives is not new and secretary professional competence of teachers are not enough and the teaching method is too traditional and curriculum is unreasonable. Based on this situation, the paper does the digitization DRM solutions using the DRM digital control program based on multivariate intelligent teaching reform program of talent training. This paper establishes and develops the ODRL talent model and achieves the segmentation description and dynamic segmentation authorization of tasks and contents of minority secretary major secretary courses. It also achieves the secondary development of DRM under the ODRL control model and verifies the feasibility and reliability of the training mode using the teaching effect evaluation method of OpenAPI, which provides a reliable theoretical basis for the reform of minority secretary major training model.
\end{abstract}

\section{Introduction}

Cloud computing is a new calculation model which has broad application prospect [1]. The multivariate intelligent computing is a branch of cloud computing which has the synthesis and diversification of calculation. If the DRM control model can be used, we can achieve diversification processing and analysis of data. With the growth of the diversified trend of English application, the growing of minority secretary major translator needs diversity talent. Based on this situation, the paper proposes minority secretary major multivariate cultivation model of DRM control model. This paper formulates dynamic sub-division of minority secretary major teaching task which treats professional knowledge, intercultural communication and practical knowledge as the main content according to the feedback surveys of 30 schools [2-4]. Finally, it analyzes the effectiveness of teaching using the OpenAPI experimental model and establishes the experimental algorithm which proves the feasibility and reliability of the DRM control model minority secretary major training program.

\section{The training mode introduction of OpenAPI Experimental Model secretary talents}

The DRM control technology has been widely used in digital rights management. However, due to the segmented dynamic smart recognition, it can be used in diversified design of secretary courses [5]. The time of minority secretary major training model is not too long. It exposed many drawbacks of talent training after the students' work of minority secretary major such as weak secretary expertise, poor intercultural communication and inadequate practice. This paper surveys the working ability after the students' work of minority secretary major of 30 schools using the form of questionnaire. It also gathers the data of the employer and the performance of students and gets the survey result as shown in Figure 1. 


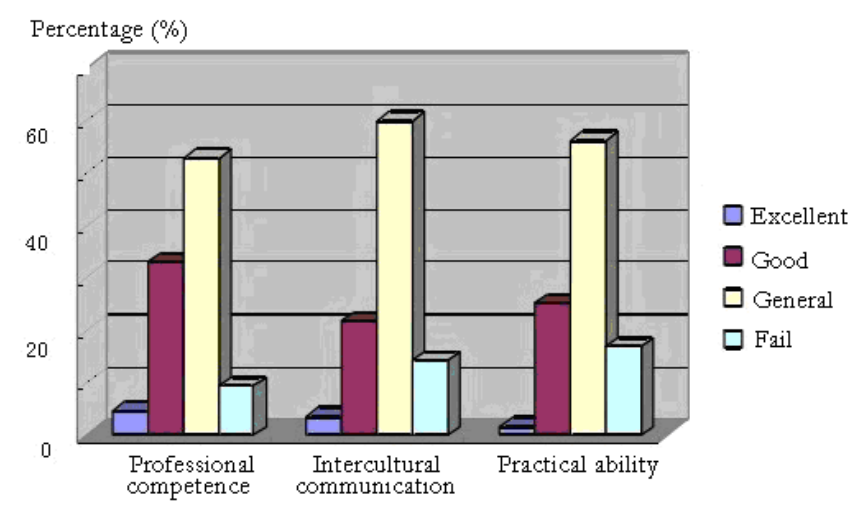

Fig.1 the statistics of minority secretary major students' performance

From the Figure, we can see that the capacity performances after the English secretary students' works of 30 schools are concentrated in the general level. The worst performance is intercultural communication and the practical ability [6]. A lot of people are fail. The relatively good performance is professional competence. So, we should strengthen the comprehensive training of minority secretary major secretary talent and achieve the diversification talent training effect. According to these shortages, this paper proposes talent diversified program under DRM control model. The specific flow chart of the implementation of the program is shown in Figure 2.

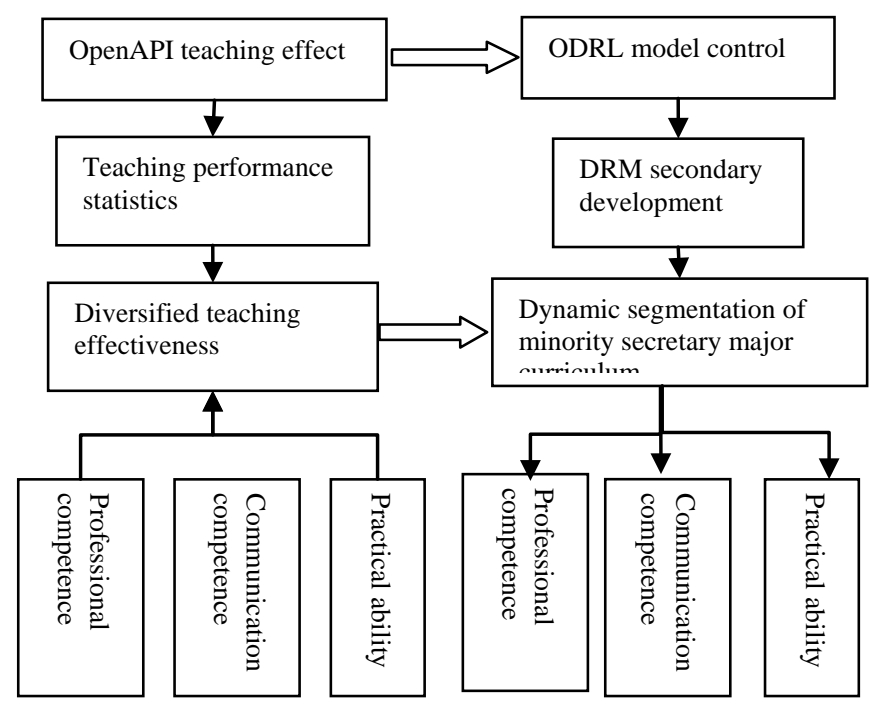

Fig.2 DRM minority secretary major secretary training model

As is shown in the Figure, DRM control mode of minority secretary major secretary personnel training is been developed and designed based on the OpenAPI teaching effect [7,8]. It determines the dynamic allocation of teaching curriculum through the comprehensive survey of professional competence, intercultural communication and practical ability. It also achieves the optimized and rational allocation of curriculum of minority secretary major secretary training model through the ODRL model control and secondary development of DRM.

\section{Control Model of OpenAPI Experimental Model multidimensional secretary talent training}

The talent training model established by DRM can be put into practical application through reliability analysis. This paper establishes DRM random reliability model using related theoretical knowledge of reliability properties. Reliability can be described with a set of functions. When a random variables influence the reliability of DRM,the performance function of structure is:

$$
F=f\left(y_{1}, y_{2}, \ldots, y_{a}\right)
$$


When $F>0$, The DRM control model in a reliable state;

When $F=0$, The DRM control model in a limited state;

When $F<0$, The DRM control model in a fail state;

And the function is:

$$
F=f\left(y_{1}, y_{2}, \ldots, y_{n}\right)=0
$$

This function is limit state equation of structure which is the key basic of structural reliability analysis.

Monte - Carlo method is called Statistical experimental method, stochastic simulation method and random sampling technique which is a numerical methods solving the probability of failure directly developed with the development of computer [9]. It has been considered as a relatively accurate method in the current structural reliability calculations.

We can use the DRM control programming general program and generate a random number:

$$
X_{e}(e=1,2, \ldots, u)
$$

We can generate a set of random numbers $X_{i j}$ which meet the probability distribution of the random variable $X_{i j}$ according to distribution form of random variables $Y_{e}(e=1,2, \ldots, u)$ and equivalent transformation [10]. It puts it into the limit state function $X_{k}\left(X_{1}, X_{2}, \cdots, X_{m}\right)$ and gets a set of random variables $S_{j}(j=1,2, \ldots, n)$ of limit state function. If there are ${ }^{m_{1}}$ random numbers less than $\mathrm{O}$ in $n$ random numbers and $n$ is large enough, the frequency is close to the probability according to large numbers law. The structural failure probability is:

$$
Y=f(Z \leq 0)=m_{1} / n
$$

In Figure 3, we can see that the establishment of reliability models of DRM multiple training mainly use the large numbers law to determine the random number and then use intelligent data management to achieve diverse intelligent DRM control teaching and determine the teaching program finally.

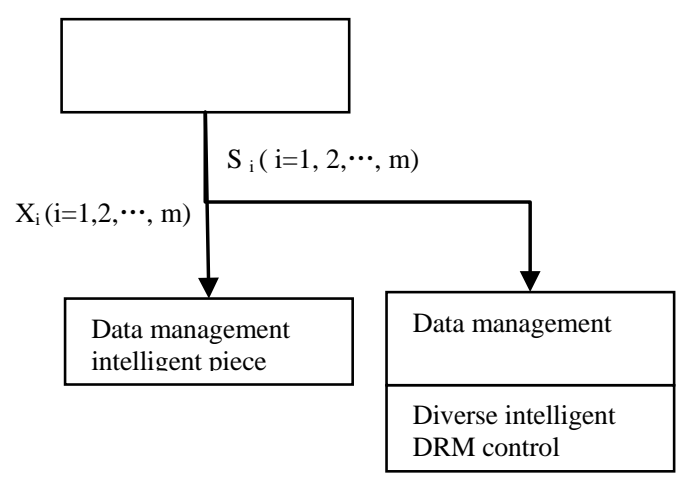

Fig.3 The reliability model of DRM multiple training

\section{Research on the DRM multidimensional secretary talent training model}

The design and evaluation of multidimensional secretary talent training model mainly rely on the reliability of DRM model control [11]. It establishes random variables distribution function and limit state equation according to minority secretary major professional capacity, cultural communicative competence and understanding and practical ability. The specific process is shown in Figure 4. 


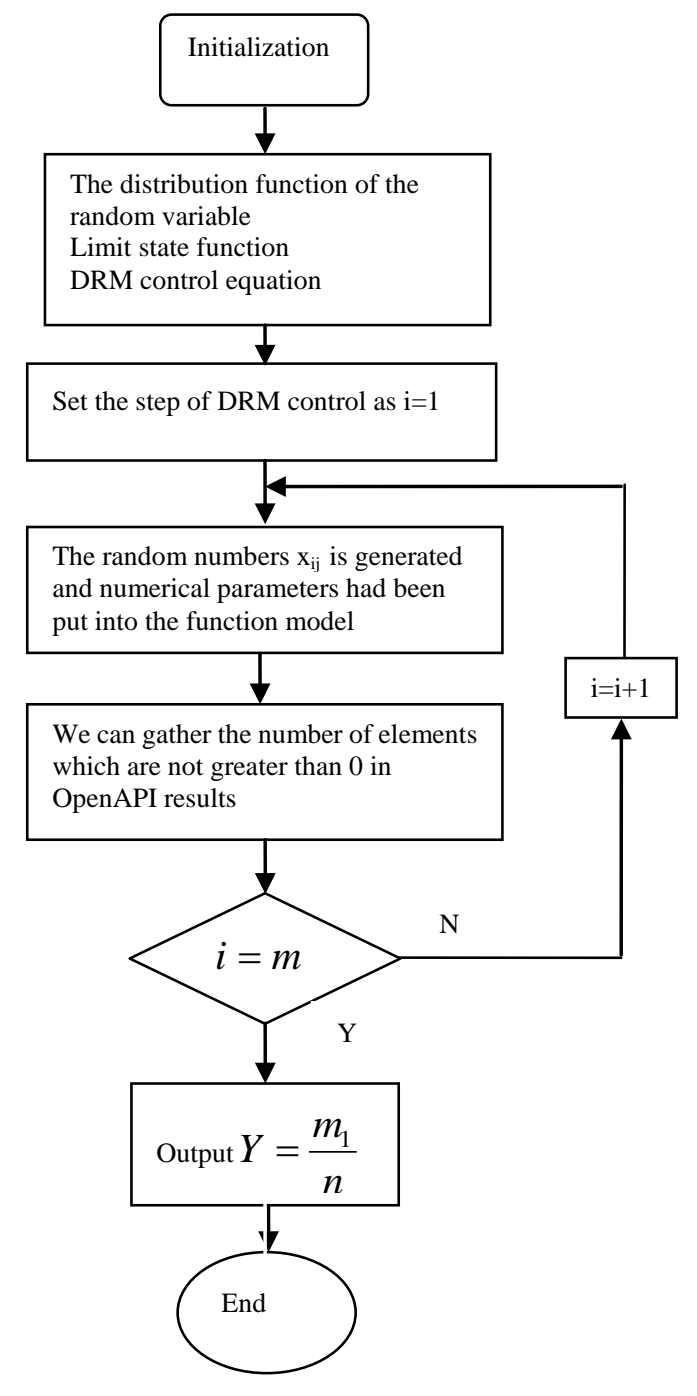

Fig.4 The flowchart of OpenAPI effect reliability

From the Figure, we can see that the talent training method of minority secretary major DRM control model is through the random sequence to analyze. We should set the step after random number. When OpenAPI which is not greater than 0 and $\mathrm{m}$ are not the same, we can stop the calculation. If not, we can continue to calculate.

Table 1 Curriculum set DRM appraisal form

\begin{tabular}{|c|c|c|}
\hline Course set & $\begin{array}{c}\text { OpenAPI } \\
\text { effect }\end{array}$ & $\begin{array}{c}\text { Relia } \\
\text { bility }\end{array}$ \\
\hline $\begin{array}{c}\text { secretary } \\
\text { professional } \\
\text { competence }\end{array}$ & 0.75 & 0.72 \\
\hline $\begin{array}{c}\text { Translate cultural } \\
\text { communication }\end{array}$ & 0.78 & 0.85 \\
\hline Practice cognition & 0.8 & 0.78 \\
\hline
\end{tabular}

From the experimental table, we can see that DRM minority secretary major secretary training model is a intelligent diversified training program which combined secretary professional competence, translate cultural communication and practice cognition. From the evaluation of teaching effectiveness of OpenAPI, we can see that the three aspects have no great distinctions. Practice cognitive ability has improved and it occupied the largest proportion. From the reliability point of view, reliability of the secretary communicative cultural content is larger. DRM and 
diversified training mode, secretary communicative cultural competence has been fully improved which verifies the feasibility and reliability of the DRM secretary training model.

\section{Conclusion}

According to digital management model DRM control model and reliability analysis, this paper studied the cultivation of minority secretary major . The first part proposed employability feedback statistics of minority secretary major secretary of 30 schools' students. From the statistical data, we can see that capacity performances are concentrated in the general level after working. There are a lot of people who are failing in intercultural communication and the practical ability. The second part of the paper established reliability mathematical model of DRM talent training mode. It used the model to analyze the reliability of OpenAPI of teaching effectiveness in the third part. The OpenAPI effect of practical cognitive ability is the highest-0.8. The reliability of secretary file communicative ability is the largest-0.85. Secretary major training plan has shortage of teaching content and lacks cross-cultural communication training program. Its teaching mission objectives is not new and secretary professional competence of teachers are not enough and the teaching method is too traditional and curriculum is unreasonable. Based on this situation, the paper does the digitization DRM solutions using the DRM digital control program based on multivariate intelligent teaching reform program of talent training. This paper establishes and develops the ODRL talent model and achieves the segmentation description and dynamic segmentation authorization of tasks and contents of minority secretary major secretary courses. It also achieves the secondary development of DRM under the ODRL control model and verifies the feasibility and reliability of the training mode using the teaching effect evaluation method of OpenAPI. It provided the data reference for the training of minority secretary major the cultivation of minority secretary major should follow the principle of compound talents training mode and improve the overall quality of the talent of minority secretary major .

\section{References}

[1] Quanquan Wu. The basic research on "Double Type" teachers of the vocational Education [M]. Beijing: Tsinghua University Press, 2011(03):23-24.

[2] Yang Bai. The theory and practice of International secretary personnel training in foreign language universities [M]. Beijing: Economic Management Press, 2011: 82-102.

[3] Aiqin Wang, Xiuping Wang. The cultivation of compound applied secretary personnel training in market economy [J]. Taizhou University, 2010, (5): 78-83.

[4] Guoying Qian. The transformation of higher education and the cultivation of application-oriented talents [M]. Hangzhou: Zhejiang University Press, 2010(02):23-36.

[5] Jingzhi Wei, Yixian Yang, Xinxin Niu. Research on OMADRM technology system [J]. Electronic information reported, 2011, 12 (03): 33-34.

[6] Meihua Wang, Kefeng Fan, Zhanwu Wang. OMA DRM technology architecture analysis [J]. Network security technology and applications, 2010.23 (06): 23-24.

[7] Yaqin Zhang. The future of computing in the "cloud" [J]. Information systems engineering, 2011.15 (10):55-56.

[8] Panyan Chuan. The rational use of English movies as curriculum resources[J]. Contemporary education forum. 2010, (4):21-23.

[9] Chunlin Guan. The significance of demand analysis in minority secretary major curriculum [J]. Foreign language and foreign language teaching, 2010, (3):23-34. 
[10] Xiaohong Jiang. The thinking of composite English personnel training paradigm [J]. Higher Studies, 2011, (3):137-138.

[11] Zhongxia Mao. The study of needs analysis of minority secretary major curriculum [D]. Hunan University; 2010(04):12-33. 